\title{
Towards predictive models of landscape geochemistry in deeply weathered terrains using electromagnetics
}

IGNACIO GonZALEZ-ALVAREZ ${ }^{1 *}$, ANDREW KING ${ }^{1}$, YUSEN LEY-COOPER ${ }^{1}$

(1) CSIRO, 26 Dick Perry Avenue, Kensington WA 6151, Perth, Western Australia

\section{INTRODUCTION}

Nearly $25 \%$ of the Earth's continental surface area is affected by tropical climatic conditions that result in intense chemical weathering. These areas often display lateritic profiles that may reach depths of up to $100 \mathrm{~m}$. Understanding the geology of these regions is problematic due to the lack of fresh bedrock outcrop and their complex weathering histories, as many of these areas display weathered profiles, which have been developing for millions of years. Thus, many of these regions correspond to ancient, stable and weathered landscapes, as is the case for several regions in Australia.

\section{REASONING}

The development of links between landscape geochemistry in deeply weathered terrain and geophysical datasets is a key element to understand better the extent and evolution of weathering. Intensely weathered landscapes can be characterized by delineating their stratigraphy, relative age and depth. This allows the generation of 3D models of the cover architecture and, therefore, the delineation of weathering fronts. This combined approach contributes to the generation and evolution of predictive and detective models of the geochemical evolution of a landscape since it has the potential to provide lateral and vertical trace element dispersion.

The data density and the depth of ground penetration $(>400 \mathrm{~m})$ of airborne electromagnetics (AEM) is ideally suited for inferring the buried geology between known stratigraphic cover profiles. AEM has the potential to significantly improve weathered cover architecture reconstruction and, therefore, the interpretation of the landscape geochemistry, erosion and deposition. However, inversion of AEM data for conductivity structure of the ground is non-unique: many different models are consistent with the data. Typically, the smoothest model is chosen, out of those that fit the data, so that structure will not be present unless required by the data (e.g. fig 2(B)). However, by including geological constraints in the geophysical inversion, such as knowledge of the number of layers, and the conductivity value ranges for different lithologies, we aim to produce inversion models like fig 2 (C) of depths to layer boundaries, rather than conductivities.

In this study we present specific models on the interpretation of AEM for deeply weathered terrains, to understand better the complex weathering processes and their implications for geochemical dispersion in areas of overprinting weathering.

Understanding landscape evolution and quantifying uncertainty

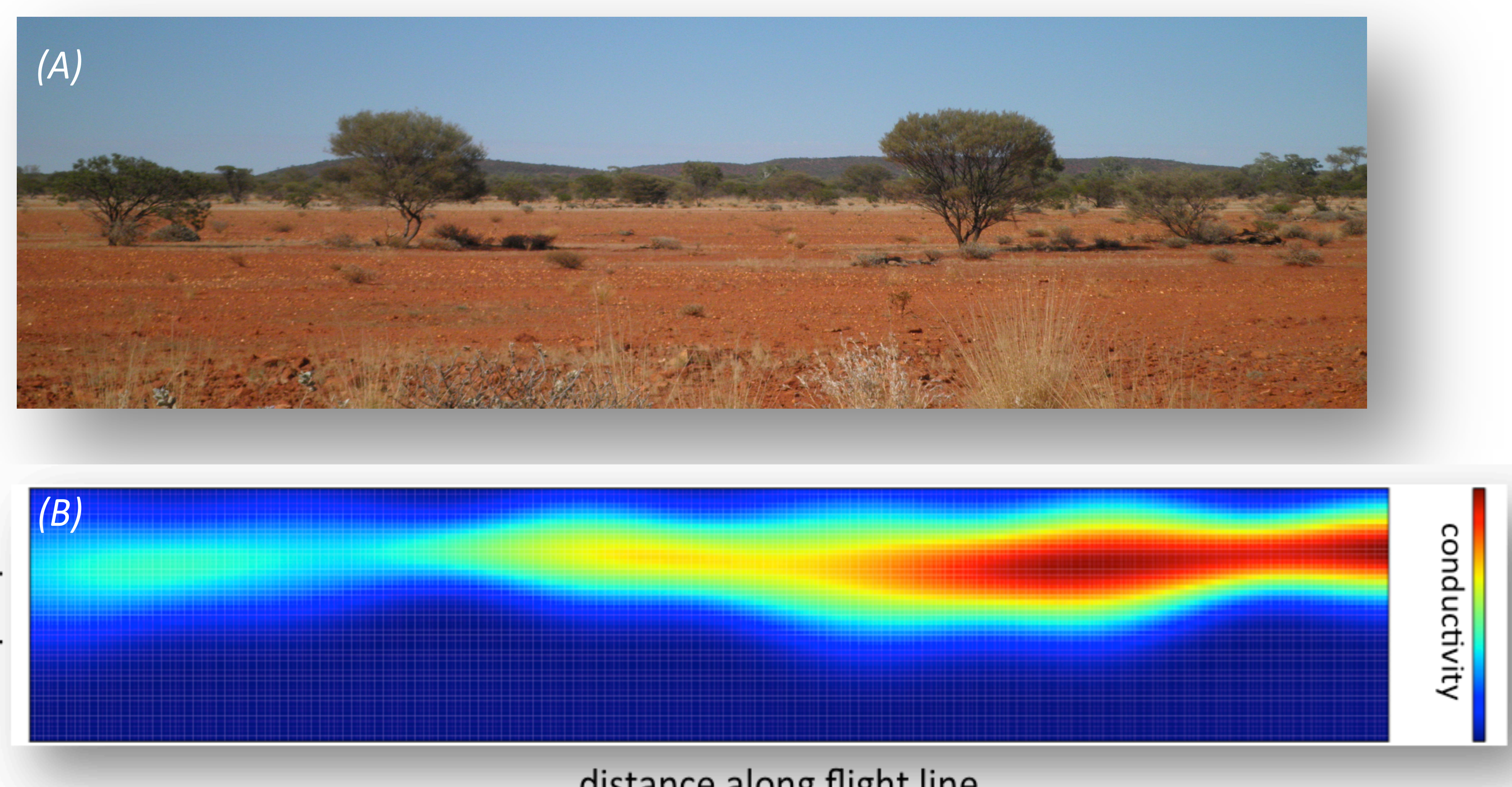

distance along flight line
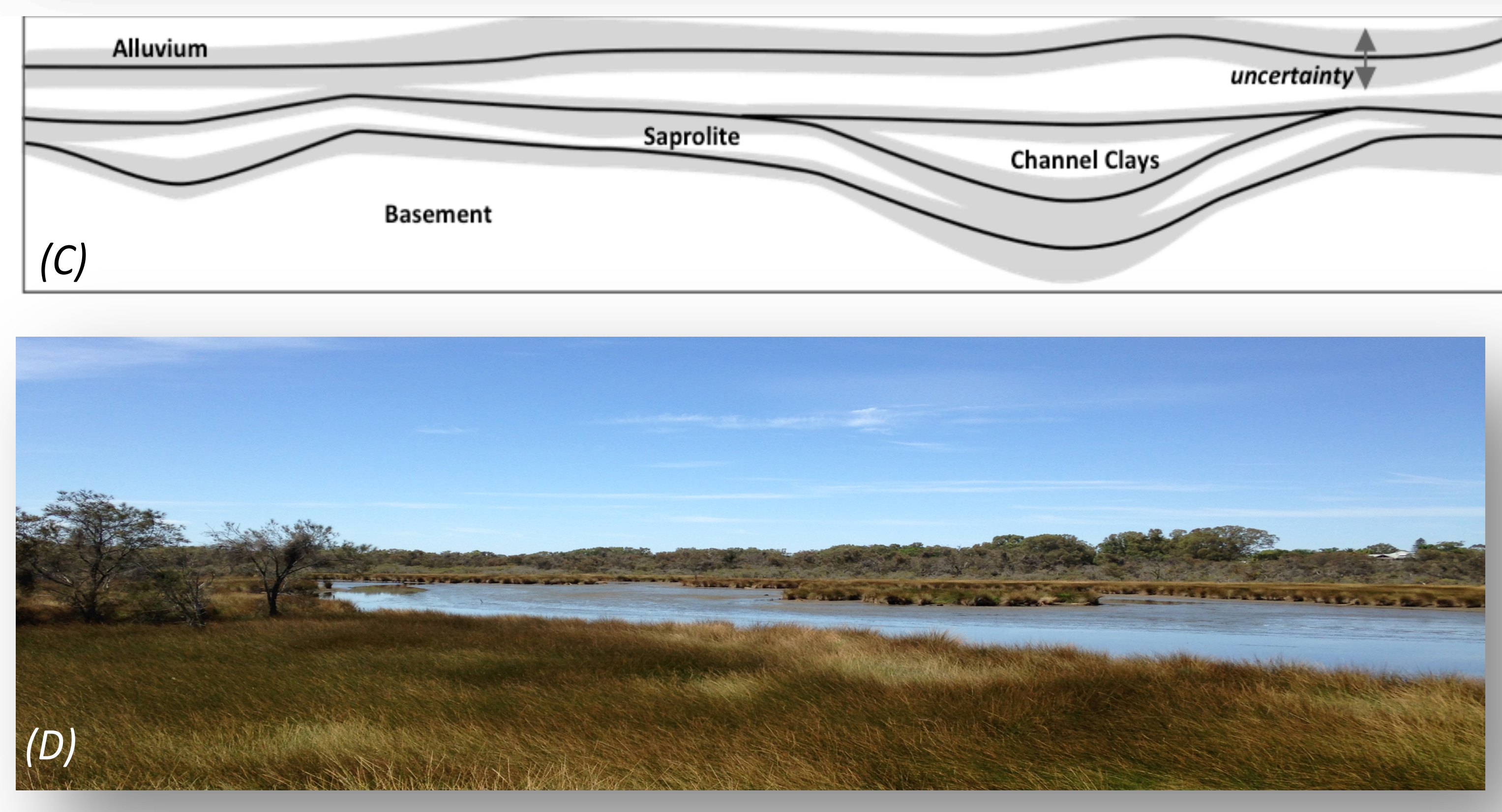

Figure 2. (A) Modern landscape at DeGrussa. (B) Possible inverted AEM model of smooth conductivity,

作
Geological and regolith context



Characterising electrical properties of regolith materials using:
AEM data
Lithology, mineralogy and geochemistry from
drilling
Basement geology
Hydrogeology
Landscape evolution
Sedimentary evolution and stratigraphic
variability
Weathering

Petrophysics

Data fusion
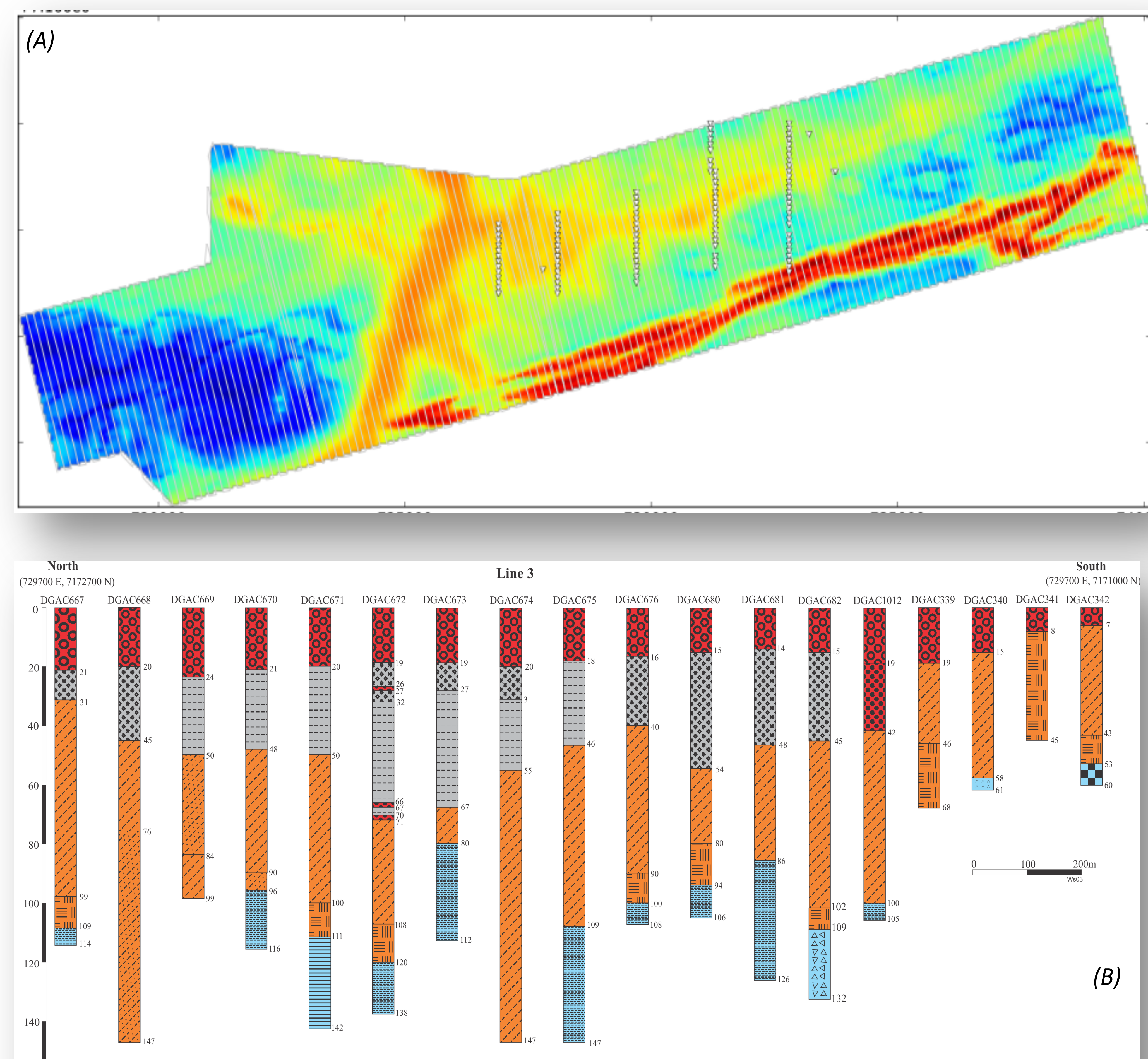

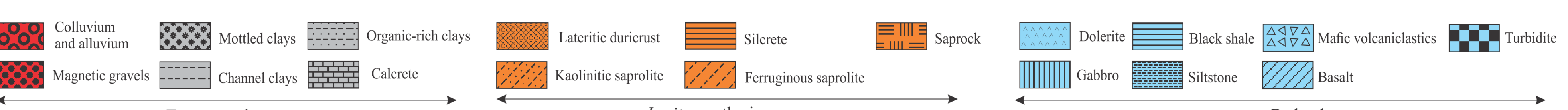

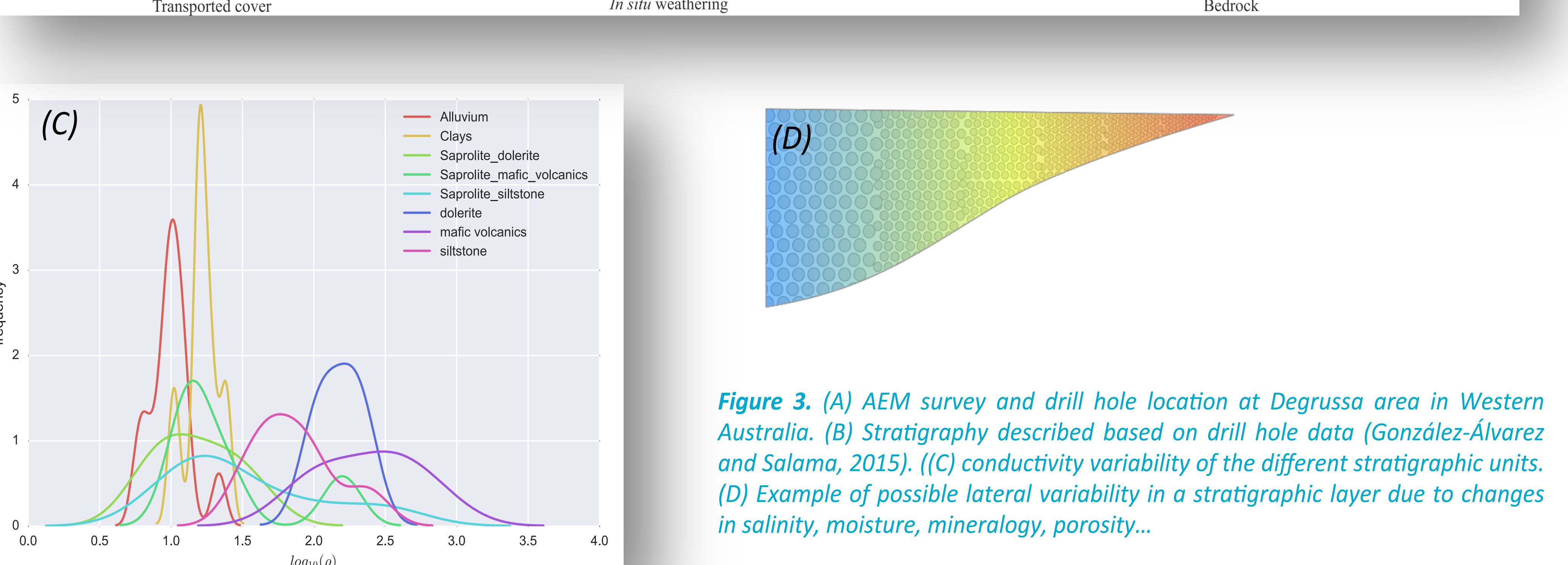

Vision for mineral exploration

Based on two main datasets: EM and drilling (coupled with its derivative datasets) such as stratigraphy, mineralogy, geochemistry... ), EM data can be processed using the contextual known geological knowledge as the constraints for the mathematical variables to build a model. This model would quantify uncertainty and will be the result of the fusion of the geological knowledge with the EM data, and therefore, tailored to that specific area studied. 